\title{
SMART AQUARIUM MENGGUNAKAN SENSOR LIGHT DEPENDENT RESISTOR BERBASIS INTERNET OF THINGS
}

${ }^{1}$ Reza Kharisma Ramadhani, ${ }^{2}$ Dedy Abdullah, ${ }^{3}$ Rozali Toyib

${ }^{1,2}$ Universitas Muhammadiyah Bengkulu, Indonesia

${ }^{3}$ Universitas Komputer Indonesia, Indonesia

rrezakharisma242424@gmail.com; '2dedy_abdullah@umb.ac.id;

; rozalitoyib@umb.ac.id;

\section{Article Info}

\section{Article history:}

Received, 12-12-2020

Revised, 15-01-2021

Accepted, 29-01-2021

\section{Kata Kunci:}

ikan

aquarium

sensor

Internet Of Things
Keywords:

fish

aquarium

sensor

Internet Of Things

\begin{abstract}
ABSTRAK
Manusian adalah individu unik yang mempunyai hobi memelihara hewan ataupun tumbuhan sebagai sarana untuk menhilangkan stress dan kejenuahan dari rutinitas sehari-hari seperti memeliharah ikan hias di aquarium baik ukuran kecil maupun besar yang tidak memerlukan ruangan yang cukup luas dan bisa juga hobi sebagai fengshui menurut kepercayaan orang-orang thiongoa, tentu memeliharah ikan di di aquarium tentunya berbeda penanganan seperti di alam liar yang ketersedia makananya teredia oleh alam tentu dengan aquarium yang medianya ukruannya relative kecil butuh penangan yang lebih dan tidak semua orang mempunyai pengetahuan dan waktu untuk menangani hewan peliharaan mereka maka dibutuhkan suatu alat yang dilengkapi dengan aplikasi untuk mengontrol suhu, PH air, pencahayaan dan pemberian pakan otomatis maka dibuat alat menggunakan sensor-sensor Berbasis Internet Of Things. Berdasarkan hasil pengujian : sensor ultrasonic akan bekerja bila jarak $7 \mathrm{~cm}$ maka pakan akan otomatis terisi kembali, bila suhu dibawah $30^{\circ} \mathrm{C}$ maka otmatis akan dilakukan pemanasan, pencahayaan normal bila bernilai 100Lux dan sensor Turbidity mendeteksi kekeruhan bila NTU di bawah 12 maka akan dilakukan pengurasan dan semua perangkat terhubung dengan Internet Of Things pada smartphone.
\end{abstract}

\section{ABSTRACT}

Human beings are unique individuals who have a hobby of raising animals or plants as a means of eliminating stress and boredom from daily routines such as keeping small and large ornamental fish in aquariums, both small and large, which do not require a large enough space and can also be a hobby as fengshui according to people's beliefs -Thiongoa people, of course keeping fish in the aquarium is of course different handling like in the wild where food is available by nature, of course with an aquarium whose medium size is relatively small it requires more handlers and not everyone has the knowledge and time to handle their pets so it is needed a tool that is equipped with applications to control temperature, water $\mathrm{PH}$, lighting and automatic feeding, a tool is made using Internet of Things-based sensors. Based on the test results: the ultrasonic sensor will work when the distance is $7 \mathrm{~cm}$, the feed will automatically be refilled, if the temperature is below $30^{\circ} \mathrm{C}$ then it will automatically warm up, normal lighting if it is 100Lux and the Turbidity sensor detects turbidity if the NTU is below 12 then draining will be carried out and all device connected to the Internet Of Things on a smartphone

\section{Penulis Korespondensi:}

Rozali Toyib

Program Studi Informatika,

Universitas Muhammadiyah Bengkulu

Email: rozalitoyib@umb.ac.id 


\section{PENDAHULUAN}

Manusia adalah individu yang unik mereka suka petualang dan suka mengkoleksi baik itu benda mati maupun benda hidup seperti memelihara hewan bisa hewan darat maupun air, khususnya hewan air yaitu ikan menjadi trending orang-orang untuk memeliharah ikan baik itu ikan hias maupun ikan yang dianggap bisa menarik rezeki menurut kepercayaan khusus orang-orang tionghoa, ikan hias menjadi favorit masyarakat Indonesia menjadi salah satu hewan peliharaan karena keindahaan baik dari bentuknya yang beraneka ragam serta cocok menjadi panjangan sebagai hiasan di rumah. Merawat dan memilihara ikan hias bisa untuk menghilangkan stress dan hobi untuk mengusir kebosanan karena tingkah, keunikan serta karatristik dari masing-masing jenisnya. Menurut survey pemilik hewan peliharaan Nasional tahun 2019-2020 yang dilakukan Asosiasi hewan peliharaan Amerika serikat sekitar 13 juta orang biasanya memilik hewan peliharaan yaitu ikan menjadi jenis hewan menduduki pringkat ketiga setelah kucing dan anjing. Jenis ikan hias yang biasa dipelihara seperti Ikan Maskoki (Carassius auratus), ikan arwana (Sclerophages formous), Ikan cupang (Beta splendens) Ikan guppy,_Ikan Louhan, Ikan Koi, Ikan Komet, Ikan Platy serta jenis yang lainnya, karena ikan hias ini adalah ikan yang unik biasanya pemeliharaan didalam aquarium yang tidak terlalu membutuhkan ruangan yang besar, untuk itu diperlukan pemeliharan ekstra karena berbedah dengan yang dialam yang relative beradaptasi dengan lingkungan dan ketersedian makanan yang banyak. pada aquarium ikan-ikan tersebut membutuhkan perawatan yang baik terkait pemberian pakan, tingkat kekeruhan, dan suhu air yang berbeda-beda tiap jenisnya. pemberian pakan merupakan hal yang penting dalam pembudidayaan ikan, pemberian pakan ikan yang manual memiliki kekurangan yang berpengaruh terhadap pertumbuhan ikan seperti, kesalahan penjadwalan dan tidak terkontrolnya takaran pakan yang di berikan, pemberian pakan yang terlalu sering dan berlebihan akan mempengaruhi kesehatan ikan, karena sisa makanan tersebut akan bercampur dengan kotoran sehingga menjadi amonia dan terdekomposisi menjadi nirit yang berbahaya bagi kesehan ikan. Ikan berisiko terkena dampak buruk apabila menetap pada air keruh yang terekspos partikel halus, salah satu parameter yang penting adalah suhu air kolam. Suhur air kolam ini sangat berpengaruh karena memiliki dampak terhadap organisme yang ada pada kolam seperti: Mempengaruhi distribusi mineral dalam air dan mempengaruhi kosentrasi oksigen terlarut dalam air, fenomena meningkat dan menurunnya suhu air akan menyebabkan ikan mengalami kesulitan untuk melakukan proses mobilisasi energi dan ikan akan mati dalam waktu yang sangat cepat.

Permasalahan diatas menjadi persoalan besar bagi mereka yang tidak punya pengetahuan yang baik dan waktu yang cukup dalam pemeliharaan ikan hias di aquarium, bukan bisa menghilangkan stress dan kebosanan yang ada menambah permasalahan baru karena akan mengakibat kerugian yang besar karena salah penanganan untuk itu dibutuhkan suatu alat yang mungkinkan untuk mengatasi persoalan-persoalan diatas dengan membuat smart aquarium dengan menggunakan sensor Light Dependent Resistor Berbasis Internet Of Things, perancangan alat ini menggunakan sensor GE turbidity untuk mengukur tingkat kekeruhan air kolam ikan dan motor servo yang berfungsi membuka plat wadah pakan ikan sehingga pakan yang berada dalam wadah dapat ditumpahkan, selanjutnya data dari sensor tersebut akan diolah oleh Mikrokontroler sebagai pengendali, akan dihasilkan keluaran berupa tulisan warning pada LCD diikuti dengan nyala LED apabila nilai kekeruhan melewati batas ambang yang telah ditentukan.

Pada penelitian sebelumnya Arduino Atmega 2560 digunakan dalam perancangan smart aquarium berbasis internet of things digunakan untuk mempermudah bagi para penghobi ikan hias dalam pemeliharaan dan perawatan ikan di dimana dipasang sensor yang bisa menunjukan indikator sepertisuhu air, volume serta PH air dan secara otomatis bisa menghidupkan serta mematikan perangkat di dalamnya seperti pompa, heater dan pompa air, Masalah kualitas air adalah salah satu kesulitan bagi penghobi ikan hias karena sangat sensitif terutama bagi jenis ikan tertentu seperti Arwana Silver dimana media pemeliharaan harus benar-benar menjadi perhatian seperti suhu, parameter fisika dan kekeruhan maka digunakan sensor Arduino dengan ponsel Android sebagai media kontrolnya di aquariumnya [1]-[2].

Penelitian bertujuan Membuat alat otomatisasi pada aquarium yang memungkinkan u ntuk mendeteksi kekeruhan air, sistem akan menguras bak dan memasukkan air bersih secara otomatis, dan pemberi makan otomatis dengan menggunakan sensor light dependent resistor yang dikendali melalui smartphone untuk mempermudah bagi pemilik untuk merawat ikan peliharaannya. 


\section{A. Aquarium}

Aquarium adalah suatu bahan yang terbuat dari plastik ataupun kaca tembus pandang yang di isi air diman ditempat berbagai macam tumbuhan, benda mati dan hewan air dimana dilakukan pengaturan suhu air, Suatu tempat yang didalamnya ada tumbuh-tumbuhan, binatang dan benda mati bisa berupa batu-batuan yang berupa ruang/kolam/bak yang tranfaran dengan tujuan untuk dipamerkan

\section{[3]-[4].}

\section{B. Internet of Things (IoT)}

Internet of things adalah merupakan konsep dalam pemanfaatan dari suatu koneksi internet yang terhubung secara kontinyu yang menghubungkan antara mesin, sensor jaringan dan akuator untuk mengirimkan data melalui jaringan infformasi secara indefenden [5]. Internet of things bekerja dengan memanfaatkan program dengan perintah-perintah dengan adanya interaksi dan komunikasi secara otomatis antara mesin yang terhbung dengan dengan internet melalui perangkat atau media penghubung [6].

\section{Sensor}

Sensor/tranduser adalah alat mekanis digunakan untuk mendeteksi panas, sinar dan kimia untuk melakukan pengukuran/pengendalian menjadi arus dan tegangan listrik yang didalamnya terdapat komponen seperti chip mikrokontroler dan AVR yang deprogram melalui prangkat computer, Sensor digunakan oleh perusahan Air PDAM untuk mengukur debet air yang digunakan oleh pelanggan melalui pipa-pipa air dengan menggunakan sensosr debet air dengan satuan waktu per meter melalui suatu luas penampang [7]-[8].

\section{Sensor Ultrasonik}

Sensor ultrasonic merupakan menggunakan gelombng suara yaitu sekitar $40 \mathrm{KHz}-400 \mathrm{KHz}$ yang dipantulkan ke sebuah benda yang sfesifik dengan frekuensi tertentu untuk menafsirkan eksistyensi sebuah benda [9]. Disebut sensor ultrasonic dikarenakan penggunaan gelombng ultrasonic dengan frekuensi tertentu bisa mencapai $20000 \mathrm{~Hz}$ yang tidak terdengan oleh indra manusia hanya oleh hewan tertentu saja dan sensor ini merubah bunyi menjadi besaran listrikdari pantualan kea rah benda yang ditujuh [10].

\section{E. Sensor Turbidity}

Sensor Turbidity SEN0189 adalah sensor yang digunakan untuk mengukur kekeruahan dengan batas pengoperasian temperature 5 OC-900 OC serta keasaman air dengan batas 0-14 PH dengan bluetooth HC05 sebagai koneksinya menggunakan smartphone[11]. Sensor ini akan mengukur kekeruhan air dan kemudian nilainya kan ditampilkan ke layar LCD dimana satuan yang dipakai adalah NTU[12].

\section{F. Sensor Suhu DS18B20}

Sensor Suhu DS18B20 yang tidak membutuhkan ADC dengan mikrokontroler dalam berkomunikasi dan hanya membutuhkan 1 wire saja untuk mengukur suhu yang keluaran digitalnya yang akurasi cukup tinggi sekitar $0.5^{0} \mathrm{C}$ dengan rentang $-10^{0}-8.5^{0}$, [13]

\section{G. Sensor LDR (Light Dependent Resistor)}

Light Dependent Resistor (LDR) adalah sensor menggunakan cahaya sebgai resistor khususnya di sesuaikan dengan nilai hambatan berupa intensitas cahya sebagai sumbernya (intensitas cahaya naik) di konversikan menjadi nilai ADC[14]. 


\section{H. Motor Servo}

Motor servo merupakan perangkat actuator (Motor) dengan sistem control loop tertutup(servo) di set-up untuk menentukan posisi sudut dari poros sebgai outputnya, yang dilengkapi gear diporos motor DC digunakan untuk memperlambat putaran poros dan meningkat torsi motor servo [15].

\section{Arduino uno}

Android merupakan open source untuk rancangan mobile device menyediakan tools dan flatform framework yang lengkap dalam pengembangannya yang menyimpan informasi penting yang diperlukan dilengkapi open source database yang cukup stabil dan berukuran kecil[16]

\section{J. Modul Esp8266}

Modul ESP8266 sistem pengendalian protocol MOTT ataupun webserver yang tertanam memory IC yang merupakan modul WIFI menggunakan Aplikasi Of Thing (IOT), dengan pembacaan sensor-sensor pengendali actuator [17].

K. Aplikasi Blynk

Aplikasi BLYNK adalah software yang digunakan sebagai penghubung anatar smartphone agar bisa mengakses mikrokontroler untuk memantau jarak jauh selama perangkat masih terhubung Internet Things (IOT) kapanpu dan dimanapun penggunaanya berada [18].

\section{Water Pump}

Motor pompa suatu alat yang mengubah dari energi litrik menjadi mekanik (putaran), melalui pengantar medan magnet menghasilkan daya dorong sehingga air dapat mengalir melalui lubang bagian bawah[19].

\section{Relay}

Rangkaian driver relay dibangun dari berbagai macam komponen yang saling mendukung antara komponen satu dengan yang lain pada rangkaian elektronik yang mengendali pengoperasian dari jarak jauh yang berfungsi menyambung dan memutuskan arus listrik tanpa harus menekan saklar[20].

\section{METODE PENELITIAN}

A. System Development Life Cycle Method

Setiap tahapan akan menghasilkan apa yang dibutuhkan oleh tahapan berikutnya dalam software development life cycle tersebut. Persyaratan tersebut lalu diterjemahkan ke dalam desain. Kode pun kemudian akan diproduksi sesuai dengan desain tersebut dalam tahap pengembangan :

1. Planing

Tahap ini juga dapat mencakup pengumpulan umpan balik dari pemangku kepentingan atau pihak-pihak terkait seperti calon pelanggan, developer, perwakilan tim sales, dan pendapat ahli

2. Define requirements

Fase ini juga dimaksudkan untuk menentukan sumber daya yang dibutuhkan untuk membangun proyek seperti tim atau mesin dalam proses pengembangan aplikasi software tersebut.

3. Design and prototyping

Fase desain dalam SDLC adalah tahapan di mana kamu membuat model cara kerja aplikasi software

4. Software development

Fase ini bisa juga digunakan aplikasi Access Control atau Source Code Management untuk membantu developer melacak perubahan pada kode dan memastikan kompatibilitas antar proyek tim yang berbeda sehingga sasaran terpenuhi.

5. Testing 
Tahapan pengujian sangat penting sebelum aplikasi software digunakan pengguna. Beberapa pengujian yang biasanya dilakukan seperti security testing yang diotomatiskan, atau pengujian untuk penerapan yang kompleks

6. Deployment

Tahapan selanjutnya pada SDLC adalah penerapan. Pada fase ini aplikasi sudah tersedia pada pelanggan untuk digunakan

7. Operations and Maintenance

Pada titik ini sebetulnya aplikasi benar-benar sudah selesai dan bisa digunakan di lapangan. Namun, tahapan operasi dan pemeliharaan masih dianggap penting. Sebab, dalam tahapan ini pengguna bisa jadi menemukan bug yang tidak ditemukan selama pengujian sehingga kesalahan perlu diatasi

B. Flowchart

Flowchart sistem kerja dari sensor ultrasonik, sistem kerja sensor suhu, sistem kerja sensor turbidity, dan sistem kerja sensor LDR (http://belajarduino.blogspot.co.id).

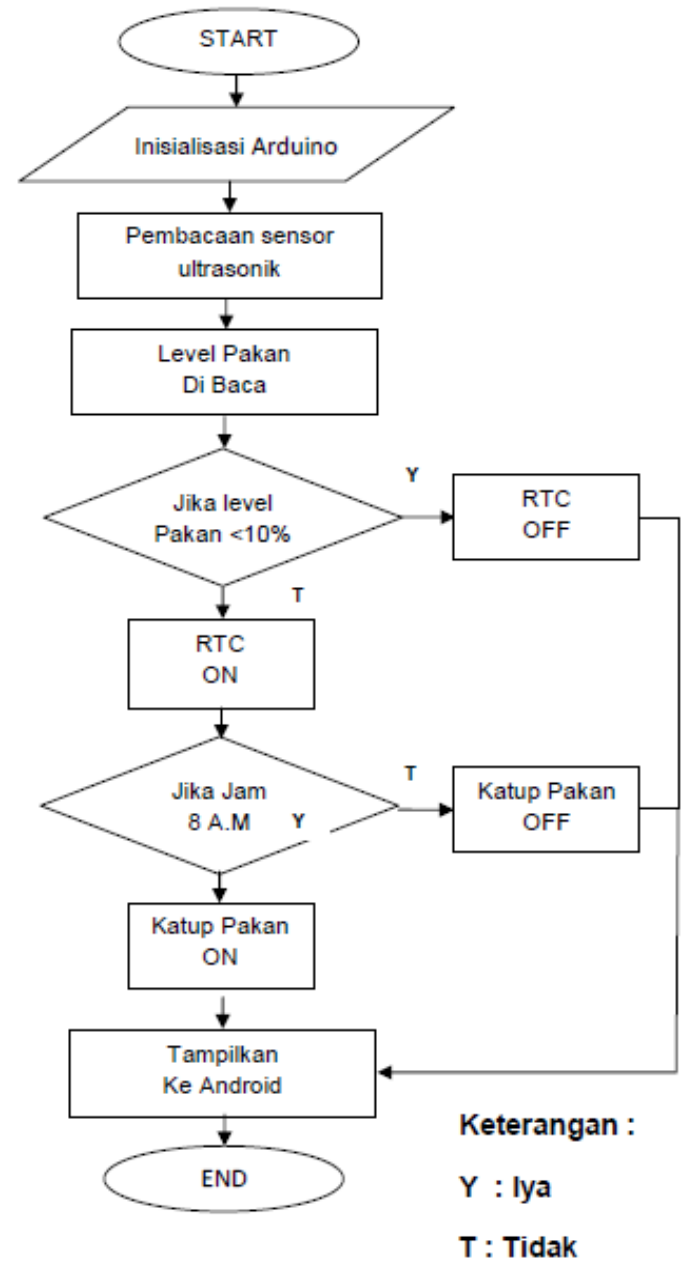

Sumber : Addin Miftachul Firdaus Program Studi Teknik Komputer, Fakultas Ilmu Komputer, Universitas Brawijaya

Gambar 1. Flowhart Sensor sensor suhu 
JSAI : Journal Scientific and Applied Informatics

Vol. 4, No. 01, Januari 2021, hal. 29 44

E-ISSN: 2614-3054; P-ISSN: 2614-3062, accredited by Kemenristekdikti, Sinta 5

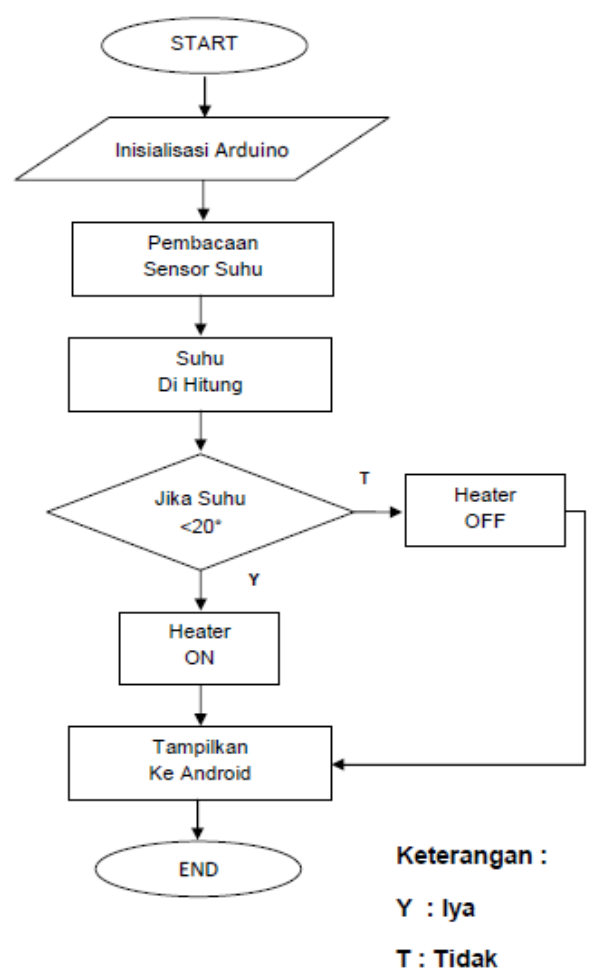

Sumber: Bibid Mulsia Hendri Politeknik Negeri Bengkalis

Gambar 2. Flowchart Pemanas

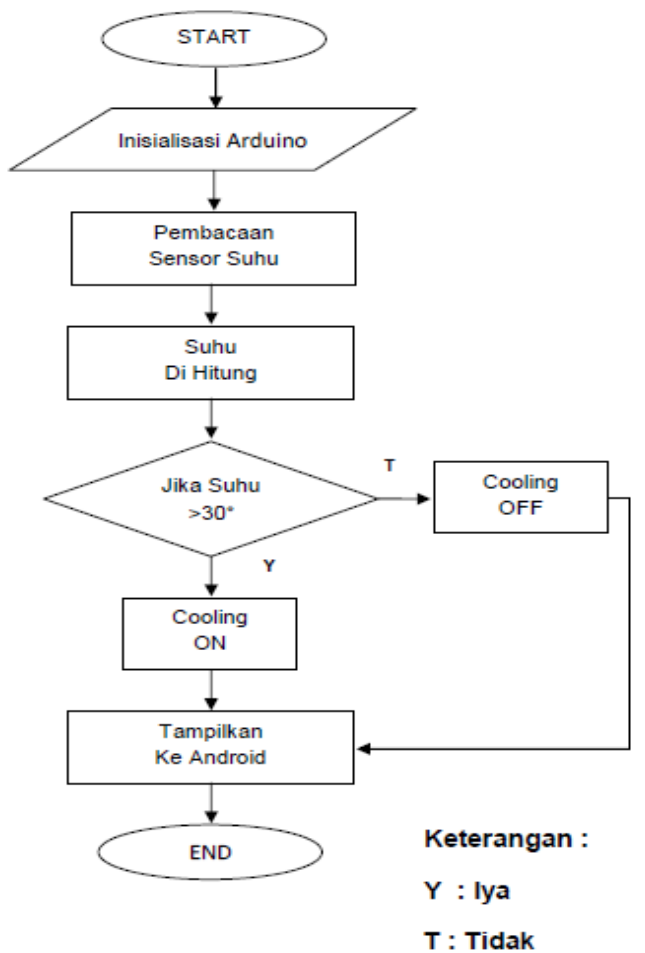

Sumber : Santo P Sigalingging Prodi S1 Teknik Elektro, FakultasTeknik Elektro, Universitas Telkom

Gambar 3. Flowchart Pendingin 


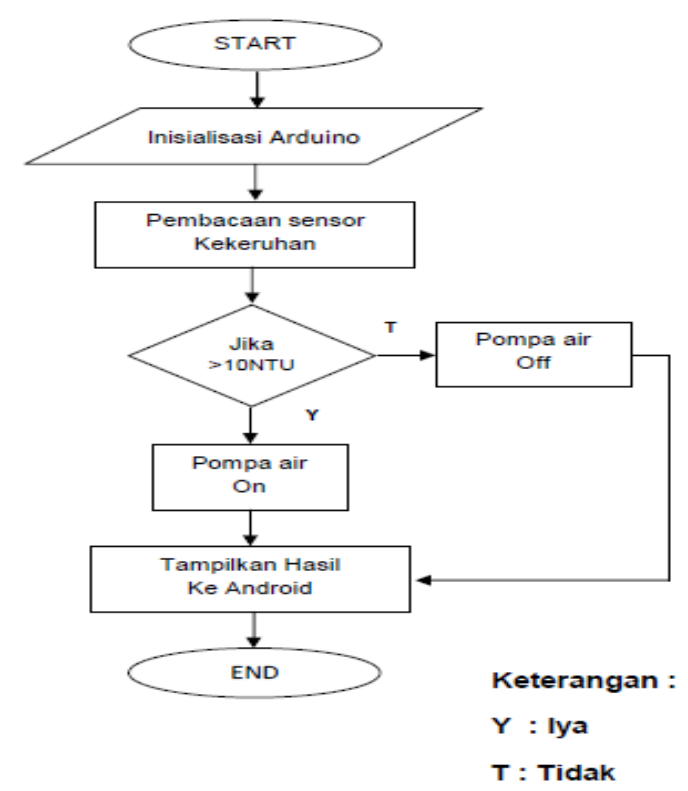

Sumber : Shaifany Fatriana Kadir Program Studi Teknik Informatika Institut Teknologi Nasional Malang

Gambar 4. Flowchart Sensor Turbidity

\section{Blok Diagram}

Perancangan skema rangkaian meliputi tahapan pengerjaan yang merupakan bagian inti dari alat. Dalam perancangan ini yang perlu diperhatikanadalah pemilihan komponen-komponen yang digunakan. Pemilihan komponen harus disesuaikan dengan kebutuhan sesuai dengandesain alat yang akan dibuat. Setelah itu barulah dilakukan percobaan dan pengetesan untuk menetapkan komponenkomponen yang akan digunakan. Pada perancangan ini ada beberapa bagian yaitu sensor Ultrasonik, sensor LDR, sensor suhu, sensor Turbidity, Arduino UNO dan Motor Servo, RTC, dan Module wifi esp8266, pompar air, relay, heater dan cooling. Adapun perancangan skema rangkaian yang akan dibuat adalah sebagai berikut :

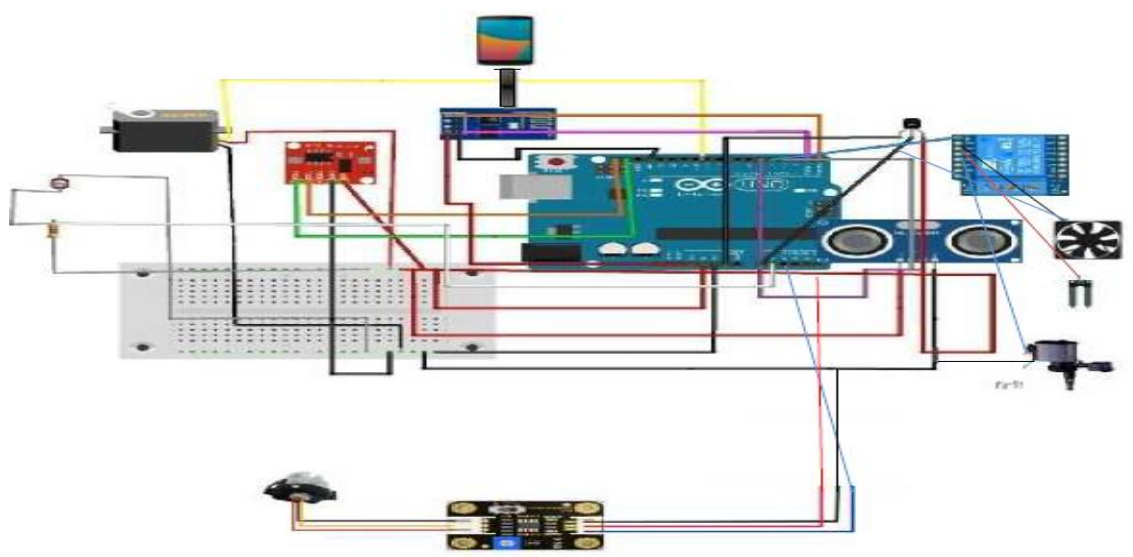

Sumber : Asmanditya Hibatullah, Program Studi Informatika Fakultas Komunikasi Dan Informatika Universitas Muhammadiyah Surakarta

Gambar 5. Rancangan Skema Smart Aquarium 


\section{HASIL DAN ANALISIS}

A. Hasil

1. Pembuatan Rangkaian

Pembuatan Robot Smart Aquarium menggunakan sensor ultrasonik, sensor suhu, sensor tubidity dan sensor light dependent resistor ini melalui beberapa tahap pembuatan. Dimulai dengan mempersiapkan bahan dan alat yang digunakan. Seperti menyiapkan Auarium dan penyusunan mainboard arduino, sensor ultrasonik, real time clock, motor servo, sensor suhu, sensor turbidity, dan sensor light dependent resistor. Maksud dari pembuatan Aquarium yaitu untuk peletakan komponenkomponen input dan output atau sebagai wadah dari system alat ini agar dapat memudahkan dan menyesuaikan sistem penggunaanya. Proses selanjutnya yaitu proses perangkain skematik elektronik robot Smart Aquarium menggunakan sensor ultrasonik, sensor suhu, sensor tubidity dan sensor light dependent resistor.

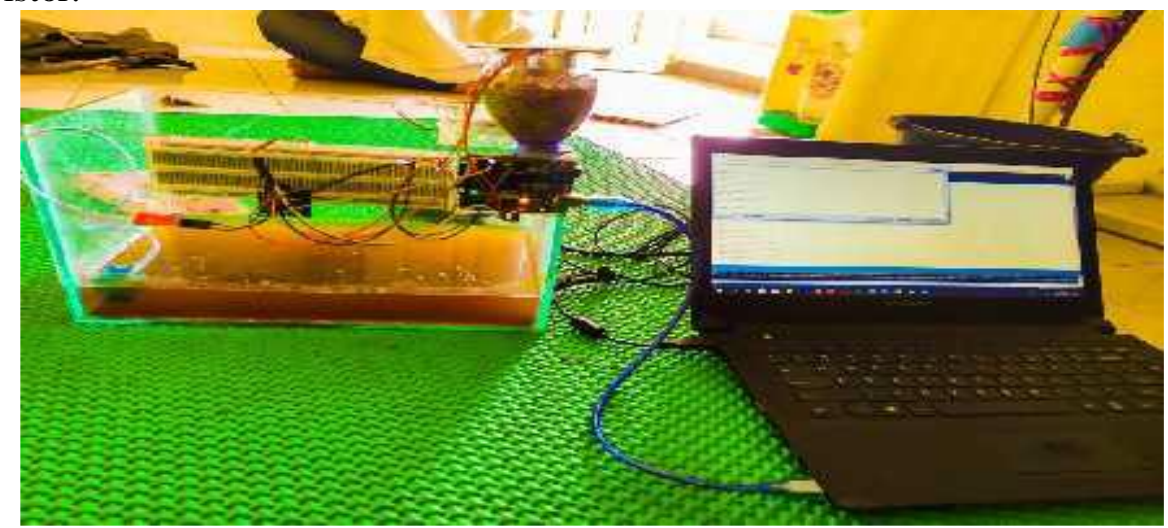

Gambar 6. Rangkaian alat dari Smart Aquarium

2. Membuat Program

Pada tahap pembuatan rangkain ini yang dilakukan adalah mempersiapkan omponen yang akan digunakan seperti sensor ultrasonik, sensor suhu, sensor tubidity dan sensor light dependent resistor (LDR), motor servo, real time clock, pompa air, heater, cooling, lampu LED, kabel jumper, kabel power supply, Arduino Uno, dan modul wifi. Pada arduino uno sudah disematkan mikrokontroler Atmega 328 yang memiliki 14 pin input/output digital (6 output untuk PWM) dan 6 pin analog. Rangkai elektronik menggunakan power supply sebagai tegangan dengan menggunakan listrik sebesar 12 Volt. Sensor Ultrasonik menggunakan pin 5 untuk input-an dan mendapat tegangan sesar 5 Volt, sensor Suhu menggunakan pin 2 dan mendapat tegangan sebesar 5 Volt, sensor Turbidity menggunakan pin A0 dan mendapatkan tegangan 5 Volt, dan sensor LDR (Light Dependent Resistor) menggunakan pin A1 untuk input-an, sensor LDR mendapatkan tegangan sebesar 5 Volt, dan pada IOT(internet of things menggunakan pin RX 3 dan TX 2 untuk memberi output.

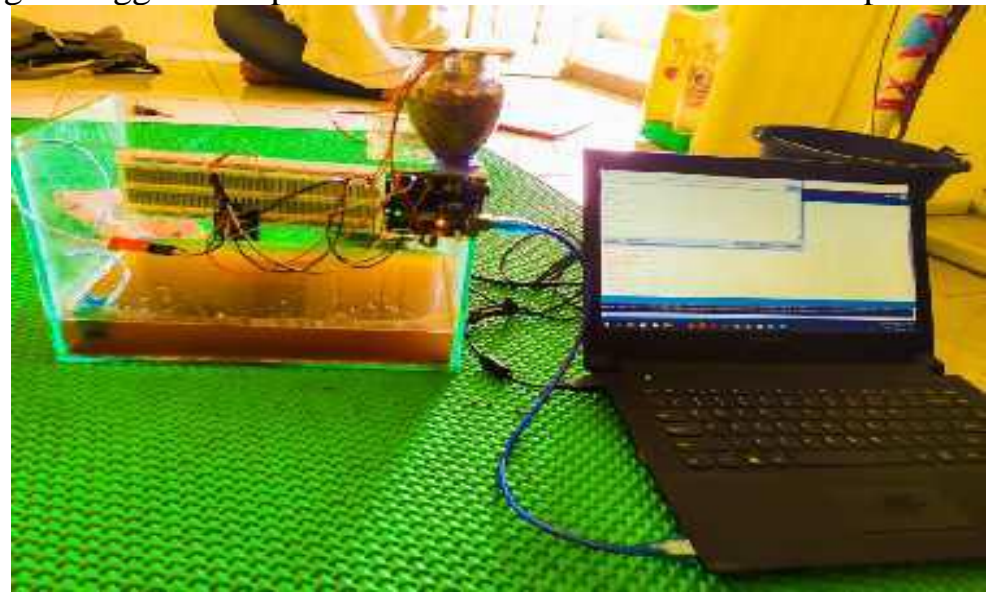

Gambar 7. Koneksi Perangkat Aqurium dengan Laptop 
3. Implementasi

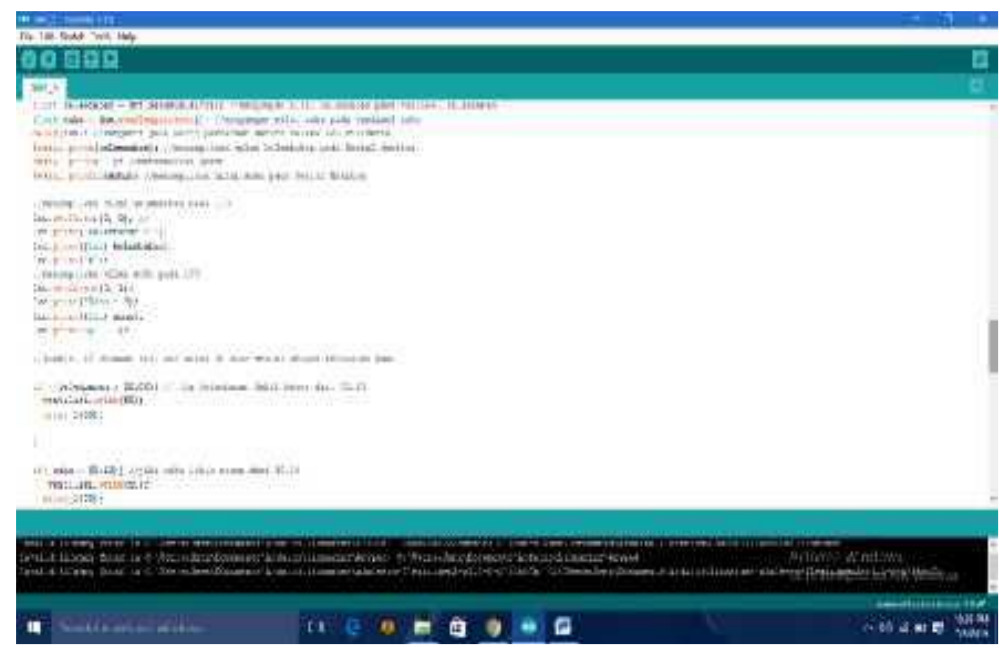

Gambar 8. Membuat Program

Setelah sistem dibangun berdasarkan rancangan yang telah dibuat maka langkah berikutnya adalah melakukan upload program. Hubungkan kabel USB dengan board arduino Uno dan pada sisi lainnya dihubungkan dengan komputer. Buka program Arduino IDE kemudian open sketch program pada rumah cerdas yang telah dibuat, selanjutnya tekan tombol upload pada Arduino IDE agar sketch ditransfer dari komputer ke board arduino. Setelah selesai melakukan upload, maka kabel USB dapat dilepas dan alat pada rancang Smart Aquarium dapat bekerja tanpa bantuan komputer lagi.

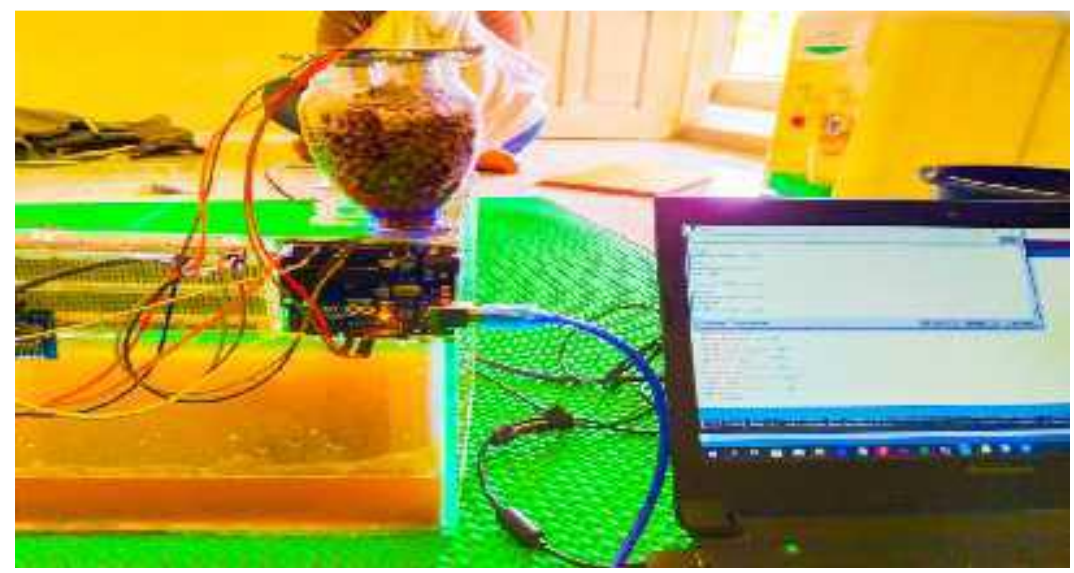

Gambar 9. Perangkat Semua Terhubung

\section{B. Analisis}

Dalam tahap yang terakhir ini semua komponen telah terhubung dengan baik dan memiliki program di dalam mikrokontroler. pengujian ini dilakukan menggunakan peraga simulasi yaitu miniatur smart Aquarium dengan cara kerja perangkat ini yaitu dengan menghubungkan kabel ke sumber daya supply arduino. Pada perangkat ini di tandai Led arduino menyala, mikrokontroler bekerja dengan menjalankan perintah yang telah di inputkan sebelumnya berupa coding, dimana coding tersebut mewakili perintah untuk menjalankan sensor ultrasonik, sensor suhu DSB18b, sensor Turbidity dan sensor LDR (Light Dependent Resistor). Sehingga menghasilkan beberapa output sesuai dengan kondisi yang terdeteksi oleh masing-masing sensor pada smart aquarium ini. Pengujian simulasi perangkat ini bertujuan untuk melihat apakah sensor, mikrokontroler dan program telah berjalan dengan baik.

a. Pengujian Sensor Ultrasonik

Pengujian yang dilakukan dalam penelitian ini yaitu melakukan pengujian pada pemberian ikan sesuai level dan waktu yang telah dilakukang pada gambar 10 menunjukan pada saat sensor ultrasonic mendeteksi level pakan. Jika terdeteksi atau terbaca oleh sensor ultrasonik maka barang bisa di program, pengujian waktu pemberian pakan yang telah dilakukan. 
JSAI : Journal Scientific and Applied Informatics

Vol. 4, No. 01, Januari 2021, hal. 29 44

E-ISSN: 2614-3054; P-ISSN: 2614-3062, accredited by Kemenristekdikti, Sinta 5

DOI: 10.36085

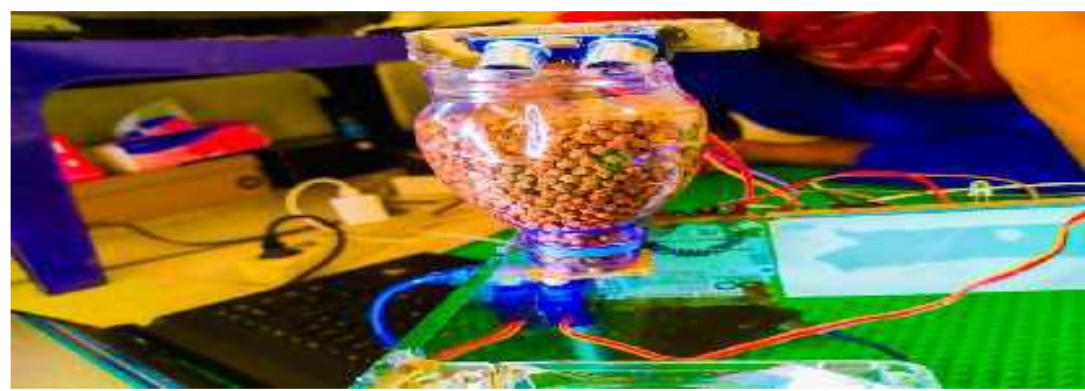

Gambar 10. Pengujian Sensor ultrasonik (level pakan)

Gambar 11 Menunjukan pada saat motor servo membuka katup pakan sesuai dengan waktu yang telah di tentukan. Jika terdeteksi atau terbaca oleh RTC dan Motor servo maka alat bisa di program.

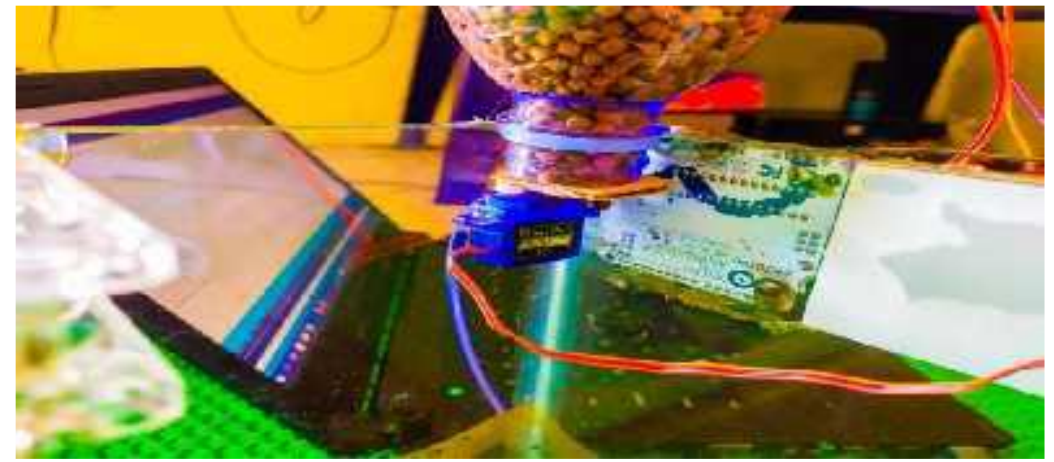

Gambar 11. Pengujian motor servo dan RTC

Tabel 1. Pengujian Sensor Ultrasonik

\begin{tabular}{lccc}
\hline NO & $\begin{array}{c}\text { Jarak Terbaca } \\
\text { oleh Sensor }\end{array}$ & $\begin{array}{c}\text { Jarak Terbaca } \\
\text { Oleh Mistar }\end{array}$ & $\begin{array}{c}\text { Keterengan } \\
\text { Pakan }\end{array}$ \\
\hline 1. & $7 \mathrm{Cm}$ & $7,5 \mathrm{Cm}$ & Kosong \\
2. & $6 \mathrm{Cm}$ & $6,5 \mathrm{Cm}$ & Kosong \\
3. & $5 \mathrm{Cm}$ & $5,5 \mathrm{Cm}$ & Setengah \\
4. & $4 \mathrm{Cm}$ & $4,5 \mathrm{Cm}$ & Terisi \\
5. & $3 \mathrm{Cm}$ & $3,5 \mathrm{Cm}$ & Terisi \\
\hline
\end{tabular}

b. Sensor Suhu DSB18b20

Pengujian alat yang dilakukan penulis pada sensor suhu adalah untuk mendeteksi suhu pendingin dan pemanas pada Aquarium. Gambar 12 Menunjukan pada saat sensor suhu mendeteksi suhu panas. Jika terdeteksi atau terbaca oleh sensor suhu maka barang bisa di program.

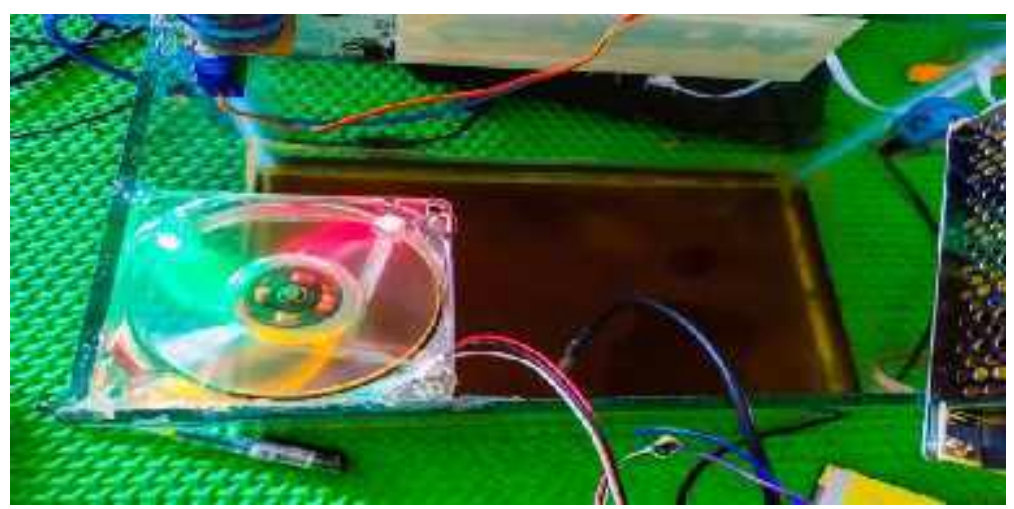

Gambar 12. Pengujian pendingin pada Aquarium 
JSAI : Journal Scientific and Applied Informatics

Vol. 4, No. 01, Januari 2021, hal. 29 44

E-ISSN: 2614-3054; P-ISSN: 2614-3062, accredited by Kemenristekdikti, Sinta 5

DOI: 10.36085

Berikut gambar 13 Pengujian waktu pemberian pakan yang telah dilakukan, Menunjukan pada saat sensor suhu mendeteksi suhu dingin, Jika terdeteksi atau terbaca oleh sensor suhu maka alat bisa di program.

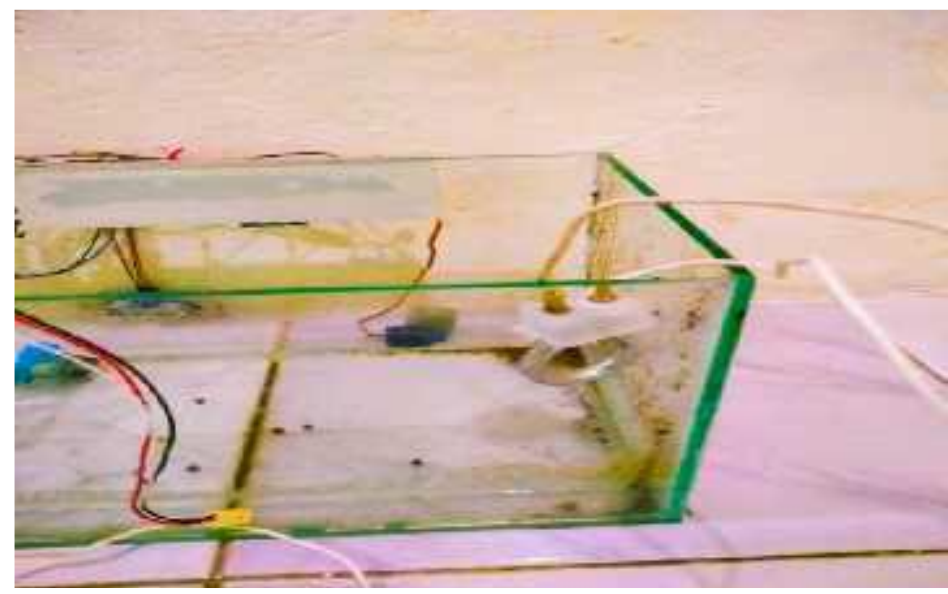

Gambar 13. Pengujian pemanas pada Aquarium

\begin{tabular}{cccc}
\hline NO & $\begin{array}{c}\text { Pembaca Suhu } \\
\text { Sensor }\end{array}$ & Thermometer & $\begin{array}{c}\text { Keterengan } \\
\text { Suhu }\end{array}$ \\
\hline 1 & $20,20^{\circ} \mathrm{C}$ & $21^{\circ} \mathrm{C}$ & Dingin \\
2 & $21,30^{\circ} \mathrm{C}$ & $22^{\circ} \mathrm{C}$ & Dingin \\
3 & $22,18^{\circ} \mathrm{C}$ & $23^{\circ} \mathrm{C}$ & Dingin \\
4 & $23,19^{\circ} \mathrm{C}$ & $24^{\circ} \mathrm{C}$ & Dingin \\
5 & $24,31^{\circ} \mathrm{C}$ & $25^{\circ} \mathrm{C}$ & Dingin \\
6 & $25,32^{\circ} \mathrm{C}$ & $26^{\circ} \mathrm{C}$ & Netral \\
7 & $26,20^{\circ} \mathrm{C}$ & $27^{\circ} \mathrm{C}$ & Panas \\
8 & $27,32^{\circ} \mathrm{C}$ & $28^{\circ} \mathrm{C}$ & Panas \\
9 & $28,17^{\circ} \mathrm{C}$ & $28^{\circ} \mathrm{C}$ & Panas \\
10 & $29,19^{\circ} \mathrm{C}$ & $30^{\circ} \mathrm{C}$ & Panas \\
\hline
\end{tabular}

c. Sensor Turbidity

Pengujian alat yang dilakukan penulis pada sensor Turbidity adalah untuk mendeteksi Kekeruhan pada air Aquarium Gambar 14 Menunjukan pada saat sensor Turbidity mendeteksi kekeruhan airmaka pompa pembuangan ON. Jika terdeteksi atau terbaca oleh sensor turbidity maka alat bisa di program.

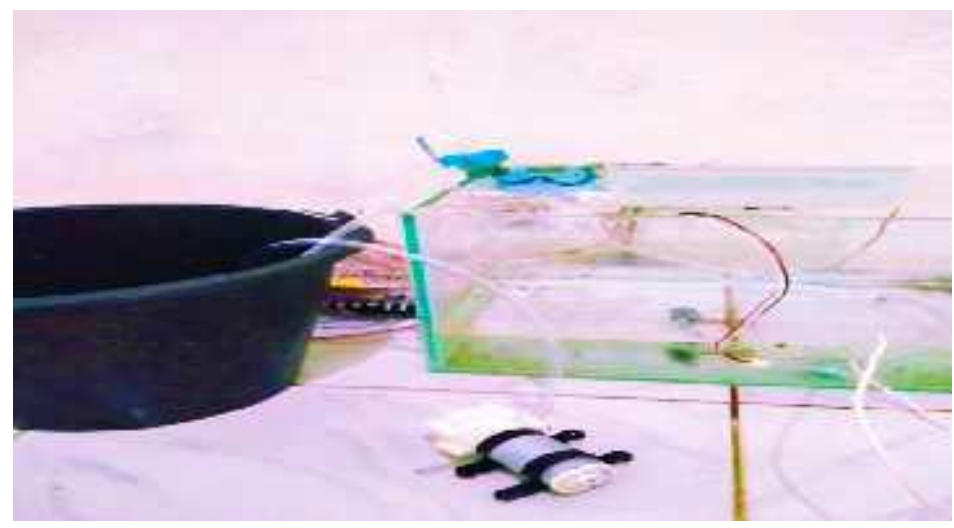

Gambar 14. Pengujian Sensor Tubidity 
JSAI : Journal Scientific and Applied Informatics

Vol. 4, No. 01, Januari 2021, hal. 29 44

E-ISSN: 2614-3054; P-ISSN: 2614-3062, accredited by Kemenristekdikti, Sinta 5

DOI: 10.36085

Tabel 3. Pengujian Sensor Turbidity

\begin{tabular}{cccc}
\hline NO & $\begin{array}{c}\text { Pembaca Kekeruhan } \\
\text { sensor }\end{array}$ & NTU & Kondisi air \\
\hline 1 & 450 adc & 10 & Keruh \\
2 & $500 \mathrm{adc}$ & 11 & Keruh \\
3 & $550 \mathrm{adc}$ & 12 & Jernih \\
4 & $600 \mathrm{adc}$ & 13 & Jerih \\
5 & $650 \mathrm{adc}$ & 14 & Jernih \\
\hline
\end{tabular}

d. Sensor LDR (Light Dependent Resistor)

Pengujian alat yang dilakukan penulis pada sensor LDR adalah untuk mendeteksi tingkat intensitas cahaya pada AquariumGambar 15 Menunjukan pada saat sensor LDR mendeteksi kegelapan maka lampu Led ON. Jika terdeteksi atau terbaca oleh sensor LDR maka alat bisa di program.

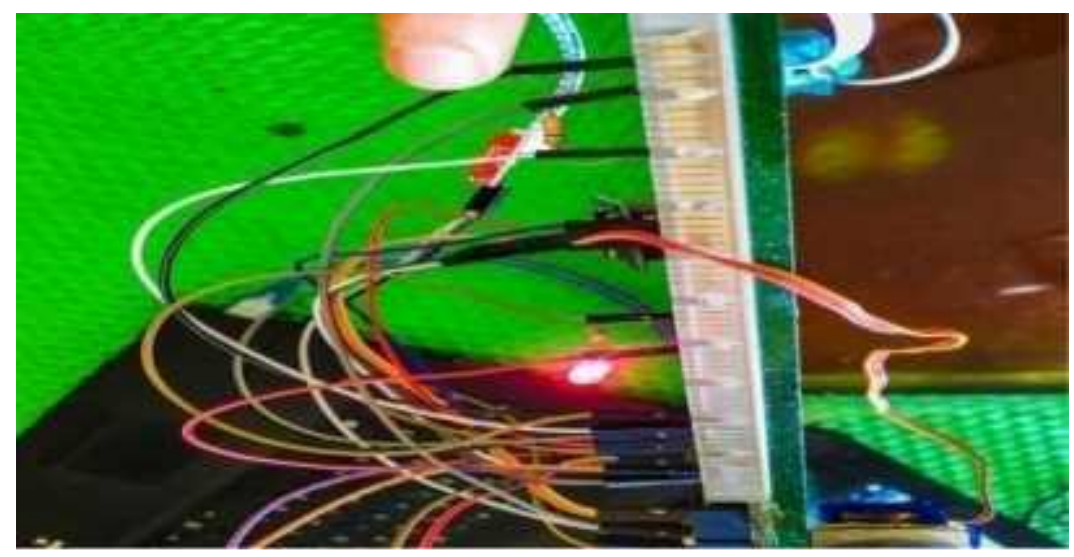

Gambar 15. Pengujian Sensor LDR

Tabel 4. Pengujian Sensor LDR

\begin{tabular}{rcc}
\hline NO & Pembaca Lux Sensor & Kondisi Aquarium \\
\hline 1 & 10 Lux & Gelap \\
2 & 20 Lux & Gelap \\
3 & 40 Lux & Gelap \\
4 & 60 Lux & Gelap \\
5 & 80 Lux & Gelap \\
6 & 100 Lux & Terang \\
7 & 120 Lux & Terang \\
8 & 140 Lux & Terang \\
9 & 160 Lux & Terang \\
10 & 180 Lux & Terang \\
11 & 200 Lux & Terang \\
\hline
\end{tabular}


JSAI : Journal Scientific and Applied Informatics

Vol. 4, No. 01, Januari 2021, hal. 29 44

E-ISSN: 2614-3054; P-ISSN: 2614-3062, accredited by Kemenristekdikti, Sinta 5

DOI: 10.36085

e. Internet of Things melalui aplikasi Android

Pada tahap perancangan software terdiri dari beberapa tahapan, yakni pembuatan source code program untuk menjalankan fungsi sensor, menghubungkan mikrokontroller dengan Wi-Fi agar dapat mengakses blynk.com dan pembuatan channels pada blynk.com sebagai penampil data dari sensor.

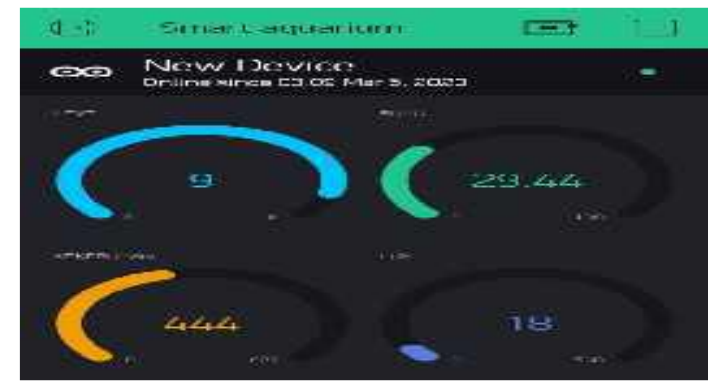

Gambar 16. Pengujian Internet Of Things di Aplikasi Android

Pengujian Internet of things di aplikasi android ini sebagai media tampilan utama yang berfungsi untuk menampilkan angka atau huruf sesuai dengan keinginan yang berdasarkan pada program yang kita gunakan. Berikut gambar pengujian dari internet of things melalui aplikasi android :

1. Pengujian Internet of Things dari Sensor Ultrasonik di Aplikasi Android

Pengujian Internet of Things dari Sensor Ultrasonik yang dilakukan penulis adalah untuk mendeteksi level pakan berupa angka dan grafik yang di deteksi dari sensor Ultrasonik ke Aplikasi Android.Gambar 4.12 Menunjukan pada saat grafik level pakan bergeser kearah angka maxsimal maka level pakan habis, jika grafik level pakan bergeser kearah angka minimal maka level pakan penuh.

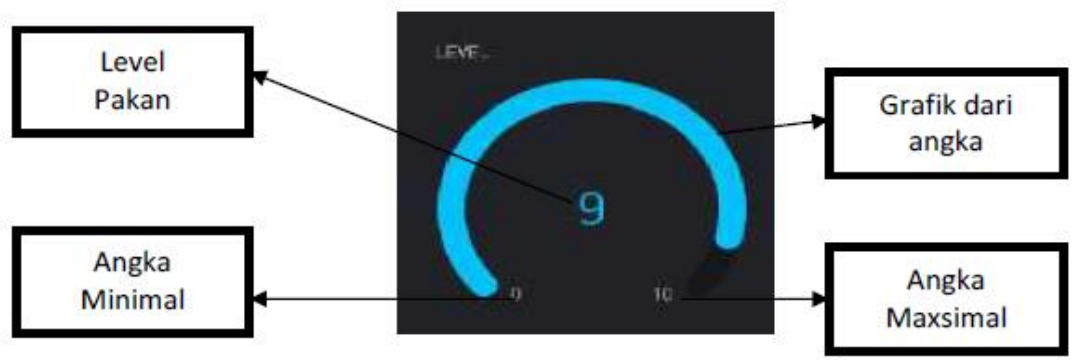

Gambar 17. Tampilan Level Pakan di Aplikasi Android

2. Pengujian Internet of Things dari Sensor Suhu di Aplikasi Android

Pengujian Internet of Things dari Sensor Suhu yang dilakukan penulis adalah untuk mendeteksi suhu derajat berupa angka dan grafik yang di deteksi dari sensor Suhu ke Aplikasi Android Gambar 18 Menunjukan pada saat grafik Suhu bergeser kearah angka maxsimal maka kondisi air dalam keadaan panas, jika grafik suhu bergeser kearah angka minimal maka kondisi air dalam keadaan dingin.

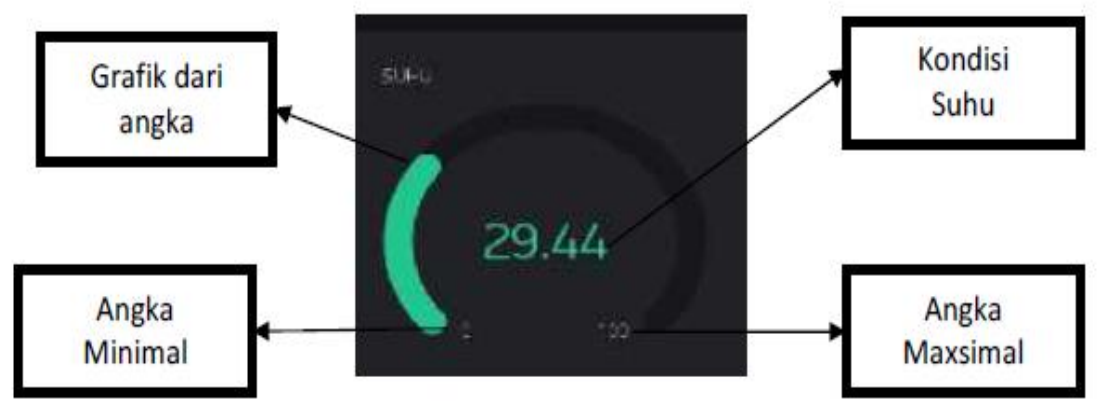

Gambar 18. Tampilan Suhu Derajat di Aplikasi Android 
JSAI : Journal Scientific and Applied Informatics

Vol. 4, No. 01, Januari 2021, hal. 29 44

E-ISSN: 2614-3054; P-ISSN: 2614-3062, accredited by Kemenristekdikti, Sinta 5

DOI: 10.36085

3. Pengujian Internet of Things dari Sensor Turbidity di Aplikasi Android

Pengujian Internet of Things dari Sensor Turbidity yang dilakukan penulis adalah untuk mendeteksi nilai NTU berupa angka dan grafik yang di deteksi dari sensor Turbidty ke Aplikasi Android.Gambar 19 Menunjukan pada saat grafik grafik turbidity bergeser kearah angka maxsimal maka kondisi air dalam keadaan jernih, jika grafik turbidity bergeser kearah angka minimal maka kondisi air dalam keadaan keruh.

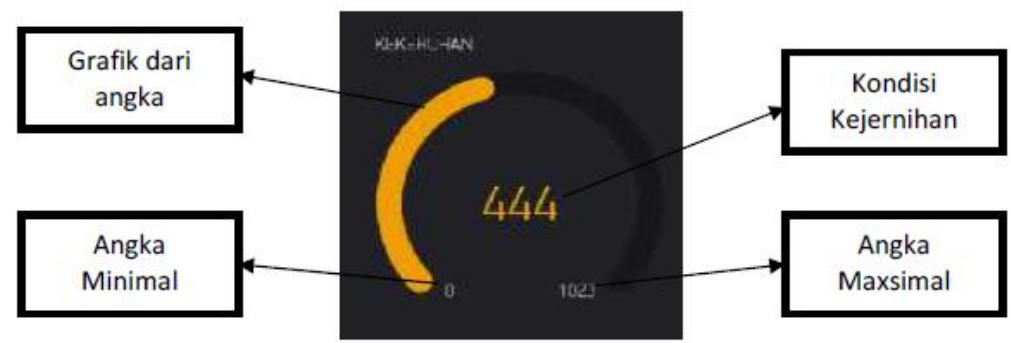

Gambar 19. Tampilan Nilai Kejernihan di Aplikasi Android

\section{Pengujian Internet of Things dari Sensor LDR di Aplikasi Android}

Pengujian Internet of Things dari Sensor LDR yang dilakukan penulis adalah untuk mendeteksi tingkat intensitas cahaya berupa angka dan grafik yang di deteksi dari sensor LDR ke Aplikasi Android Gambar 20 Menunjukan pada saat grafik grafik LDR bergeser kearah angka maxsimal maka intensitas cahaya dalam keadaan terang, jika grafik LDR bergeser kearah angka minimal maka intensitas cahaya dalam keadaan gelap.

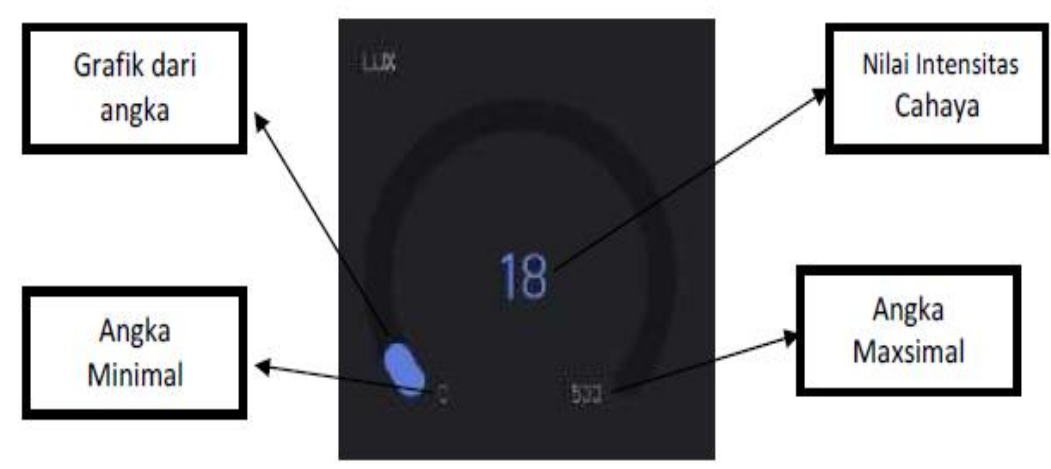

Gambar 20. Tampilan Nilai Intensitas Cahaya di Aplikasi Android

\section{KESIMPULAN}

Berdasarkan hasil pengujian: 1) Sensor Ultrasonik dengan jarak yang terbaca oleh sensor yang diinginkan berjarak $3 \mathrm{Cm}$ dikarenakan pakan dalam kondisi penuh, dengan nilai jarak maksimum 7 $\mathrm{Cm}$ dan nilai jarak terbaca minimum $3 \mathrm{Cm}$, 2) Sensor Suhu dengan suhu yang terbaca oleh sensor yang diingikan bersuhu $26^{\circ} \mathrm{C}$ dikarenakan suhu dalam keadaan netral, dengan nilai suhu panas maksimum $30^{\circ} \mathrm{C}$ dan nilai suhu dingin maksimal $20^{\circ} \mathrm{C}$, 3) Sensor Suhu dengan suhu yang terbaca oleh sensor yang diingikan bersuhu $26^{\circ} \mathrm{C}$ dikarenakan suhu dalam keadaan netral, dengan nilai suhu panas maksimum $30^{\circ} \mathrm{C}$ dan nilai suhu dingin maksimal $20^{\circ} \mathrm{C}$, 4) Sensor Light Dependent Resistor dengan pembacaan Lux sensor yang diinginkan bernilai 100Lux dikarenkan Lux dalam keadaan terang, dengan lux maksimum 200Lux dan lux minimum bernilai 10 Lux, 5) sensor Turbidity mendeteksi kekeruhan bila NTU di bawah 12 maka akan dilakukan pengurasan dan semua perangkat terhubung dengan Internet Of Things pada smartphone 


\section{REFERENSI}

\section{Bibliography\}}

[1] B. B. R. Rizko Oktaprianna', Yamato2, "RANCANG BANGUN SMART AQUARIUM MENGGUNAKAN ARDUINO ATMEGA 2560 BERBASIS INTERNET OF THINGS (IoT),” p. 6.

[2] P. Program, S. Pendidikan, T. Elektro, M. Faris, and Y. Rifqi, "Pemanfaatan smartphone sebagai sistem pengendali kondisi akuarium,” 2019.

[3] M. Ds and D. A. N. Arduino, "C, yang mempengaruhi suhu air aquarium salah satunya konsentrasi oksigen terlarut pada air. Salah satu contoh pengaruh terhadap keadan air yaitu air akan berbau tidak sedap. Konsentrasi oksigen terlarut pada air dipengaruhi Halaman 224 dari 451,” vol. 04, pp. 224 231.

[4] B. Santoso and A. D. Arfianto, "Sistem Pengganti Air Berdasarkan Kekeruhan Danpemberi Pakan Ikan Pada Akuarium Air Tawar Secara Otomatis Berbasis Mikrokontroler ATMEGA 16," J. Ilm. Teknol. Inf. Asia, vol. 8, no. 2, pp. 33-48, 2014.

[5] K. S. Budi and Y. Pramudya, "Pengembangan Sistem Akuisisi Data Kelembaban Dan Suhu Dengan Menggunakan Sensor Dht11 Dan Arduino Berbasis Iot," vol. VI, pp. SNF2017-CIP-47-SNF2017CIP-54, 2017, doi: 10.21009/03.snf2017.02.cip.07.

[6] M. A. Alipudin and et. al, "Rancang bangun alat monitoring biaya listrik terpakai berbasis internet of things (IOT)," pp. 1-11, 2019.

[7] A. R. Agusta, J. Andjarwirawan, and R. Lim, "Implementasi Internet of Things Untuk Menjaga Kelembaban Udara Pada Budidaya Jamur,” J. Infra, vol. 7, no. 2, pp. 95-100, 2019.

[8] A. Suharjono, L. N. Rahayu, and R. Afwah, "Aplikasi Sensor Flow Water Untuk Mengukur Penggunaan Air Pelanggan Secara Digital Serta Pengiriman Data Secara Otomatis Pada PDAM Kota Semarang," Tek. Elektro, Politek. negeri Semarang, vol. Vol.13, no. 1, pp. 7-12, 2015.

[9] F. Adri Achmad, S. Unang, and D. N. Ramadan, "Perancangan dan Implementasi Alat Bantu Tunanetra dengan Sensor Ultrasonik dan Global Positioning System (GPS)," e-Proceeding Appl. Sci., vol. 1, no. 2, pp. 1569-1576, 2015.

[10] Suhardi, "Pemupukan Tanaman Otomatis Menggunakan Sensor Ultrasonik Dan Cahaya Berbasis Arduino Uno R3," J. Ilmu Pengetah. dan Teknol. Islam, vol. 5, no. 1, pp. 49-61, 2020.

[11] A. Prayoga, Y. Ramdhani, A. Mubarok, and S. Topiq, "Pengukur Tingkat Kekeruhan Keasaman Dan Suhu Air Menggunakan Mikrokontroler Atmega328p Berbasis Android," J. Inform., vol. 5, no. 2, pp. 248-254, 2018, doi: 10.31311/ji.v5i2.3819.

[12] K. Rida, "Prototype Sistem Kontrol Filtasi Air Keruh Otomatis Berbasis Arduino Uno," Tugas Akhir, p. 37, 2018.

[13] E. Nurazizah, "Rancang Bangun Termometer Digital Berbasis Sensor Ds18B20 Untuk Penyandang Tunanetra ( Design Digital Thermometer Based on Sensor Ds18B20 for Blind," e-Proceeding Eng., vol. 4, no. 3, pp. 3294-3301, 2017.

[14] Eddi, C. Suhery, and D. Triyanto, "Sistem Penerangan Rumah Otomatis Dengan Sensor Cahaya Berbasis Mikrokontroler," Tugas Akhir, vol. 01, no. 2, pp. 1-10, 2013.

[15] S. Sukarjadi, A. Arifiyanto, D. T. Setiawan, and M. Hatta, "Perancangan Dan Pembuatan Smart Trash Bin Di Universitas Maarif Hasyim Latif,” Tek. Eng. Sains J., vol. 1, no. 2, pp. 101-110, 2017, doi: 10.5281/zenodo.1116487. 
JSAI : Journal Scientific and Applied Informatics

Vol. 4, No. 01, Januari 2021, hal. 29 44

E-ISSN: 2614-3054; P-ISSN: 2614-3062, accredited by Kemenristekdikti, Sinta 5

DOI: 10.36085

[16] A. F. Silvia, E. Haritman, and Y. Muladi, "Rancang Bangun Akses Kontrol Pintu Gerbang Berbasis Arduino Dan Android," Electrans, vol. 13, no. 1, pp. 1-10, 2014.

[17] R. P. Pratama, “Aplikasi Webserver Esp8266 Untuk Pengendali Peralatan Listrik,” vol. 17, no. 2, 2017, doi: 10.31227/osf.io/pjwxd.

[18] G. S. Utara, N. M. A. E. D. Wirastuti, and W. Setiawan, "Prototipe Monitoring Suhu Ruangan dan Detektor Gas Bocor Berbasis Aplikasi Blynk,” J. SPEKTRUM, vol. 7, no. 2, pp. 1-7, 2020.

[19] S. Samsugi and A. Burlian, "Sistem Penjadwalan Pompa Air Otomatis Pada Aquaponik Menggunakan Mikrokontrol Arduino Uno R3,” pp. 187-197, 2019.

[20] Alamsyah, A. Amir, and M. N. Faisal, "Peralatan Elektronik Jarak Jauh Berbasis Web," Peranc. Dan Penerapan Sist. Kontrol Peralat. Elektron. Jarak Jauh Berbas. Web, vol. 6, no. 2, pp. 577-584, 2015. 